\title{
Post-operative procalcitonin and C-reactive protein predict pancreatic fistula after laparoscopic pancreatoduodenectomy
}

Jie Ma ${ }^{1 \dagger}$, Peiqiang Jiang ${ }^{2 \dagger}$, Bai Ji², Yanqing Song ${ }^{1 *}$ and Yahui Liu ${ }^{2^{*}}$

\begin{abstract}
Background: Clinically relevant pancreatic fistula (CRPF) is a serious complication following laparoscopic pancreaticoduodenectomy (LPD). This study aimed to determine if C-reactive protein (CRP) and procalcitonin (PCT) serum levels could be used as early biomarkers to predict CRPF after LPD.

Methods: In this retrospective study, we collected peri-operative data of patients who underwent LPD between January 2019 and November 2019. We compared serum levels of white blood cells (WBC), CRP, and PCT on postoperative days (POD) 1, 2, 3, 5, and 7 between the CRPF and non-CRPF groups and analyzed the predictive risk factors for CRPF.

Results: Among the 186 patients included in this study, 18 patients (9.7\%) developed CRPF, including 15 and 3 patients with grade $B$ and $C$ fistulas, respectively. The mean WBC, CRP, and PCT levels were higher on most PODs in the CRPF group compared to the non-CRPF group. Receiver operating characteristic (ROC) analysis indicated that CRP levels on POD 2, 5, and 7 can predict CRPF development after LPD, with the area under the curve (AUC) value reaching the highest level on POD 2 (AUC 0.794). PCT levels on POD 2, 3, 5, and 7 were highly predictive of CRPF after LPD. The highest AUC value was achieved on POD 3 [PCT > $2.10 \mathrm{ng} / \mathrm{ml}$ (AUC 0.951; sensitivity 88.2\%, specificity 92.9\%, $P<0.001)$.
\end{abstract}

Conclusions: Both CRP and PCT levels can be used to predict CRPF development after LPD, with PCT having a higher predictive value.

Keywords: Laparoscopic pancreaticoduodenectomy, Pancreatic fistula, Procalcitonin, C-reactive protein

\section{Background}

Laparoscopic pancreaticoduodenectomy (LPD) was first described in 1994 [1]. Since then, LPD has been increasingly performed in high volume pancreatic centers worldwide. LPD is a challenging procedure, requires advanced laparoscopic skills, and is associated with a long learning

\footnotetext{
*Correspondence: songyanq@jlu.edu.cn; yahui@jlu.edu.cn

† Jie Ma and Peiqiang Jiang authors contributed equally to this work

${ }^{1}$ Department of Pharmacy, First Hospital of Jilin University, No. 1 Xinmin

Road, Changchun 130021, Jilin, China

2 Department of Hepatobiliary and Pancreatic Surgery, First Hospital

of Jilin University, No. 1 Xinmin Road, Changchun 130021, Jilin, China
}

curve [2]. Post-operative pancreatic fistula (POPF) is a serious complication after LPD due to the risk of secondary bleeding and intra-abdominal infections [3]. The occurrence of a POPF prolongs post-operative hospital stays and causes an increased risk of mortality. Most comparative studies of LPD and open PD (OPD) have found no significant difference in the incidence of POPF $[4,5]$. However, some studies have reported a higher incidence of POPF following LPD [6, 7]. According to recent studies, the incidence of clinically relevant pancreatic fistula (CRPF) after LPD, as defined by the 2016 International Study Group of Pancreas Surgery, ranges 
between 6.5 and $10.8 \%[2,8,9]$. Accurate prediction and timely diagnosis of CRPF after LPD is crucial for improving patient management, providing timely treatment (such as percutaneous, endoscopic, or surgical drainage), reducing hospital stay, and preventing mortality. Several studies have used radiological imaging [10], laboratory parameters [11], and clinical scoring systems [12] to predict POPF development after OPD.

White blood cell (WBC) counts, C-reactive protein (CRP), and procalcitonin (PCT) are the most commonly used markers of inflammation. Elevated blood levels of these markers are associated with inflammatory or infectious conditions. CRP and PCT have been widely used as early predictors of anastomotic leak and infection in colorectal surgery [13], gastrointestinal surgery [14], and pancreatic surgery [15]. Prior reports have demonstrated that CRP and PCT are accurate predictors of infective complications after OPD [16-19]. However, LPD is a more complex operation and requires highly skilled surgeons. Most hospitals do not perform LPD, and only some hospitals perform a few LPD operations every year, making it difficult to conduct any meaningful analysis from patient data. Furthermore, there are no published studies that report levels of inflammatory markers after LPD, let alone early predictors of CRPF. In this study, we aim to describe the kinetics of CRP and PCT after LPD and compare their usefulness for early detection of CRPF after LPD using data from our medical center.

\section{Methods}

\section{Study design and patients}

This was a retrospective analysis of data obtained from electronic medical records. Patients who underwent LPD between January 2019 and November 2019 in the Department of Hepatobiliary and Pancreatic Surgery at the First Hospital of Jilin University (Changchun, China), a large tertiary grade A hospital and high-volume pancreatic surgical center, were included in this study. The study protocol was approved and informed consent was waived due to the retrospective nature of this study by the Ethical Committee of the First Hospital of Jilin University (Ethics Approval Number: 2019-232).

All operations were performed by the same senior pancreatic surgeon with the help of a dedicated staff. There was no bias in the selection of patients. Exclusion criteria were as follows: (i) patients with symptoms and signs of active infection at the time of surgery, (ii) patients with autoimmune disorders or hematological malignancies, and (iii) incomplete clinical data.

\section{LPD procedure}

The patients were placed in a supine position with legs separated. A $12 \mathrm{~mm}$ camera port was inserted $3 \mathrm{~cm}$ below the umbilicus and pneumoperitoneum was established. The intra-abdominal pressure was maintained at $12-14 \mathrm{mmHg}$. The surgeon stood on the right side of the patient, the assistant stood on the left side, and the laparoscope holder stood between the legs of the patient. The operation was performed using the posterior colonic approach. The pancreatico-jejunal, bilio-enteric, and gastrojejunal anastomoses were performed laparoscopically as described previously [20]. Reconstruction was performed using the same technique in all the patients.

\section{Post-operative care}

All patients were transferred to the intensive care unit (ICU) for monitoring after surgery. Patients were transferred to general wards within 1-2 days once all vital parameters stabilized. All patients received prophylactic antibiotic treatment. According to the fasttrack protocol, all patients had their nasogastric tubes removed on the first day after surgery, and liquid food was administered once flatus was passed. The drainage volume was closely observed after surgery. If the drainage volume was $<50 \mathrm{~mL} / \mathrm{d}$ and the amylase level in the ascitic fluid was $<3000 \mathrm{IU} / \mathrm{L}$, the abdominal drain was removed on the third day after surgery.

The WBC count, CRP, and PCT levels were routinely measured on post-operative days (PODs) 1, 2, 3, 5, and 7 after LPD. We also collected data from pre-operative laboratory testing, intra-operative events, and postoperative outcomes.

POPF was defined in this study using the International Study Group of Pancreatic Surgery (ISGPS) 2016 criteria [21] and classified into three types: biochemical leak, grade B fistula, and grade $C$ fistula. In the present study, grade $B$ and $C$ fistulas were defined as CRPF.

\section{Statistical analysis}

Continuous variables with non-normal distribution are represented as median (Q1-Q3) and compared using the Mann-Whitney $U$ test. Categorical variables are represented as frequency (percentage) and compared using the Chi-square or Fisher's exact test. Multivariate analysis was carried out using logistic regression analysis. The best cutoff points for the predictive variables of CRPF were identified using receiver operating characteristic (ROC) curves and the Youden index. The area under the curve (AUC) of the different ROC curves were compared using Delong's test [22]. All analyses were conducted with SPSS (version 18.0, Chicago, IL, USA), and $P$ values $<0.05$ were considered statistically significant. 


\section{Results}

Baseline characteristics and post-operative course

A total of 194 patients underwent LPD during the study period. Among these patients, 8 patients were excluded due to presence of active infection $(n=3)$, presence of autoimmune disorder $(n=1)$, presence of hematological malignancy $(n=1)$, and incomplete clinical data $(n=3)$. Finally, 186 patients were included in this study. There were 102 males and 84 females with a median age of 61 years (interquartile range (IQR), 52-67). No patient required conversion to open surgery. CRPF developed in 18 patients (grade B fistula in 15 patients and grade C fistula in 3 patients). The incidence of CRPF was 9.7\%. Table 1 summarizes the patients' clinical characteristics, pre-operative laboratory data, intra-operative events, and post-operative outcomes in the CRPF and non-CRPF groups. There were significant.

differences between the two groups regarding pancreatic gland texture and pancreatic duct diameter. In addition, patients in the CRPF group had higher incidences of post-operative hemorrhage, longer hospital stays, and higher mortality rates.

\section{Comparison of trends in WBC, CRP, and PCT between two groups}

Post-operative trends of WBC counts and PCT levels were similar in the CRPF and non-CRPF groups, with a peak on POD 2 (Fig. 1a and b). CRP levels peaked on

Table 1 Comparison of clinical characteristics, pre-operative laboratory parameters, intra-operative events, and post-operative outcomes between the CRPF and non-CRPF groups

\begin{tabular}{|c|c|c|c|}
\hline Variables & CRPF group $(n=18)$ & non-CRPF group $(n=168)$ & $P$ value \\
\hline Age (years) & $64(60-69)$ & $60(52-67)$ & 0.103 \\
\hline Gender (male/female) & $7 / 11$ & $95 / 73$ & 0.152 \\
\hline $\mathrm{BMI}\left(\mathrm{kg} / \mathrm{m}^{2}\right)$ & $22.7(21.5-25.3)$ & $22.0(20.2-23.4)$ & 0.121 \\
\hline Diabetes & $2(11.1 \%)$ & $19(11.3 \%)$ & 1.000 \\
\hline History of abdominal operation & $3(16.7 \%)$ & $28(16.7 \%)$ & 1.000 \\
\hline Obstructive jaundice & $7(38.9 \%)$ & $77(45.8 \%)$ & 0.574 \\
\hline Pre-operative biliary drainage & $7(38.8 \%)$ & $53(31.5 \%)$ & 0.527 \\
\hline White blood cells $\left(\times 10^{9} / \mathrm{L}\right)$ & $5.83(5.37-7.59)$ & $5.72(4.75-6.84)$ & 0.439 \\
\hline Alanine aminotransferase (U/L) & $36.4(13.5-150.4)$ & $100.4(35.4-218.0)$ & 0.054 \\
\hline Aspartate aminotransferase $(\mathrm{U} / \mathrm{L})$ & $23.2(17.7-91.4)$ & $63.3(28.3-150.2)$ & 0.064 \\
\hline Total bilirubin $(\mu \mathrm{mol} / \mathrm{L})$ & $27.7(14.3-133.9)$ & $73.8(19.4-138.9)$ & 0.386 \\
\hline Direct bilirubin $(\mu \mathrm{mol} / \mathrm{L})$ & $19.6(3.1-92.4)$ & $47.6(6.0-98.2)$ & 0.319 \\
\hline Serum albumin (g/L) & $39.4(34.3-41.7)$ & $37.8(34.4-41.3)$ & 0.587 \\
\hline Hemoglobin (g/L) & $125(104.5-134.0)$ & $126(112.2-140.0)$ & 0.465 \\
\hline Blood creatinine $(\mu \mathrm{mol} / \mathrm{L})$ & $60.1(47.3-68.6)$ & $59.3(49.4-68.1)$ & 0.899 \\
\hline Blood urea nitrogen (mmol/L) & $4.32(3.18-6.11)$ & $4.91(3.86-5.97)$ & 0.506 \\
\hline Operation time (min) & $240(190.0-295.0)$ & $247.5(220.0-290.0)$ & 0.403 \\
\hline Blood loss (mL) & $50(27.5-50)$ & $50(30-50)$ & 0.374 \\
\hline Blood transfusion (mL) & $0(0-400)$ & $0(0-0)$ & 0.461 \\
\hline Pathology (pancreatic adenocarcinoma /others) & $3 / 15$ & $44 / 124$ & 0.569 \\
\hline Pancreatic gland texture (soft/firm) & $16 / 2$ & $98 / 70$ & 0.011 \\
\hline Pancreatic duct diameter $(<3 \mathrm{~mm} / \geq 3 \mathrm{~mm})$ & $12 / 6$ & $70 / 98$ & 0.042 \\
\hline Pathologic type (benign/malignant) & $4 / 14$ & $31 / 137$ & 0.751 \\
\hline Reoperation & $3(16.7 \%)$ & $15(8.9 \%)$ & 0.390 \\
\hline \multicolumn{4}{|l|}{ Other major complications } \\
\hline Biliary fistula & $2(5.6 \%)$ & $8(4.8 \%)$ & 1.000 \\
\hline Post-operative hemorrhage & $5(27.8 \%)$ & $9(5.3 \%)$ & 0.006 \\
\hline Delayed gastric emptying & $2(11.1 \%)$ & $24(14.3 \%)$ & 1.000 \\
\hline Post-operative hospital stay (days) & $18.0(11.5-32.5)$ & $12.0(9.0-15.0)$ & 0.010 \\
\hline Mortality (\%) & $2(11.1 \%)$ & $2(1.19 \%)$ & 0.047 \\
\hline
\end{tabular}

Data are expressed as the median [IQR] and number (percentage). Continuous variables with non-normal distribution were compared using the Mann-Whitney U test. Differences in the values of categorical variables were compared using the Chi-square test or Fisher's exact test

CRPF clinically relevant pancreatic fistula 

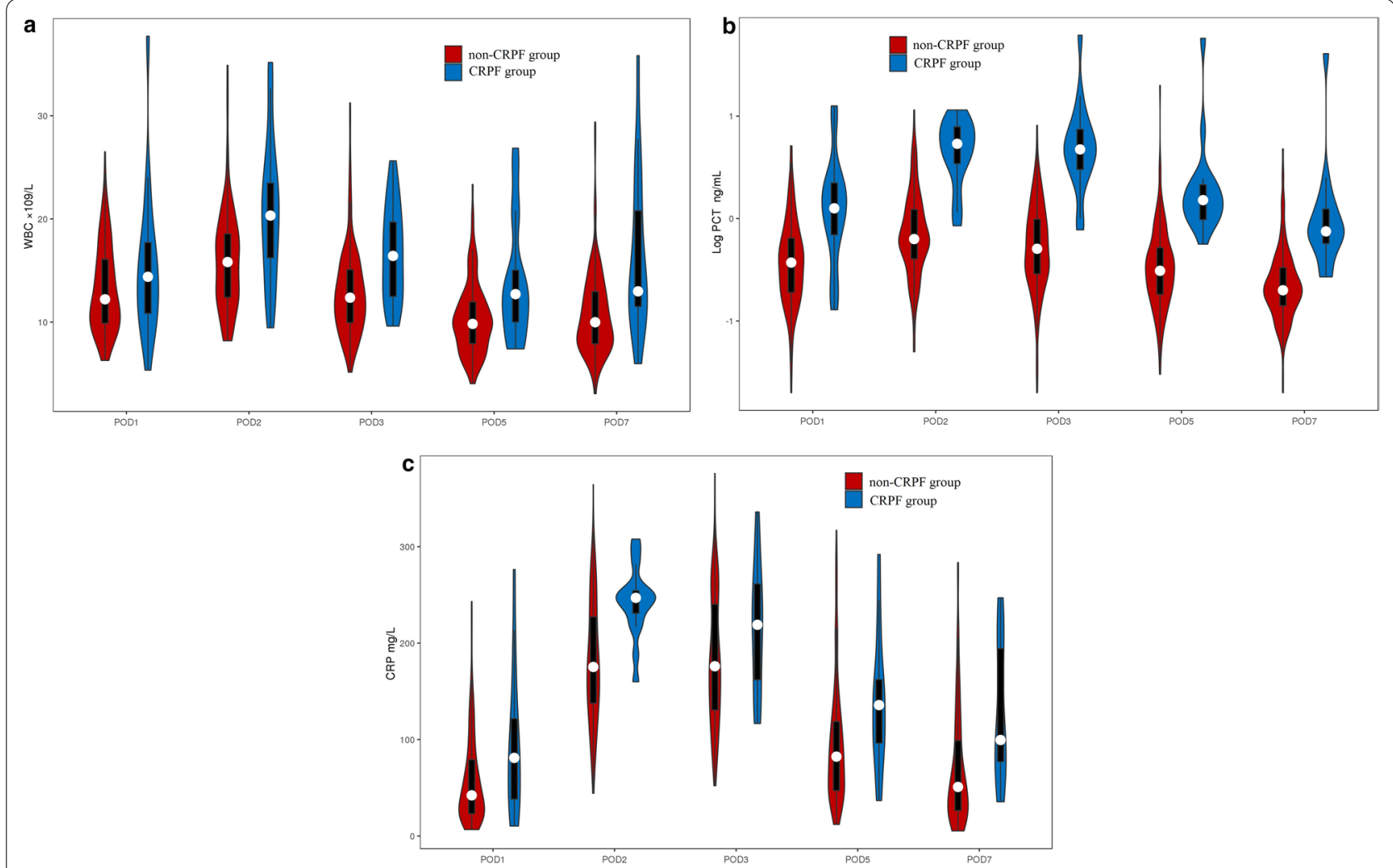

Fig. 1 Grouped violin plots showing the distribution of WBC ( $\left.\times 10^{9} / \mathrm{L}\right)(\mathrm{A}), \mathrm{PCT}(\mathrm{ng} / \mathrm{mL})(B)$, and CRP $(\mathrm{mg} / \mathrm{L})(\mathrm{C})$ in the CRPF and non-CRPF groups after LPD on PODs 1, 2, 3, 5, and 7. Considering the skewed distribution of post-operative PCT levels, we used the logarithmic variables. The shape of the distribution (extremely narrow on each end and wide in the middle) indicates that the inflammatory marker values were highly concentrated around the median. CRP C-reactive protein, WBC white blood cell, PCT procalcitonin, POD post-operative day, CRPF clinically relevant pancreatic fistula, LPD laparoscopic pancreaticoduodenectomy

POD 2 in the CRPF group and on POD 3 in the nonCRPF group (Fig. 1c). WBC counts on PODs 2, 3, 5, and 7, PCT levels on PODs 1, 2, 3, 5, and 7, and CRP levels on PODs $1,2,5$, and 7 were significantly higher in the CRPF group $(P<0.001)$. Drain fluid amylase (DFA) on POD 3 was also significantly higher in the CRPF group $(P<0.001)$ (Table 2).

\section{ROC analysis}

The AUC and cut-off values of WBC, PCT, CRP, and POD3 DFA levels were determined using ROC analysis and are listed in Table 3. Based on the AUCs obtained from the ROC plots, the diagnostic accuracy of WBC, CRP, and POD3 DFA levels were 'fair' (AUC $<0.8$ ), while the accuracy of PCT levels on PODs 2, 3, 5, and 7 was 'excellent' (AUC>0.9). The AUC obtained from the ROC plot of PCT levels was significantly higher than that of WBC and CRP levels on PODs $1,2,3,5$, and $7(P<0.05$, Delong's test). The highest AUC value for PCT was achieved on POD 3 [PCT $>2.10$ ng/ml (AUC 0.951; sensitivity $88.2 \%$, specificity $92.9 \%, P<0.001$ )] (Fig. 2 ).

\section{Multivariate analyses of predictive risk factors for CRPF in patients undergoing LPD}

Multivariate logical regression analyses revealed that POD3 PCT levels (odds ratio $(\mathrm{OR})=3.303$, 95\% confidence interval $(\mathrm{CI})$ [1.902-5.736], $P<0.001)$ and WBC counts $(\mathrm{OR}=0.282$, 95\%CI $[0.019-4.115], \quad P=0.004)$ were independent predictive factors for CRPF after LPD (Table 4).

\section{Discussion}

Post-operative pancreatic fistula (POPF) is a life-threatening complication after LPD. Various methods have been reported to predict and prevent POPF after OPD. However, LPD is a technically more demanding procedure that is only performed at a select number of surgical centers. As such, there are limited reports on the prediction of POPF after LPD. The current study was conducted at a high-volume center with nearly 200 cases of LPD being performed per year. The results of this study showed that WBC, CRP, and PCT levels were higher 
Table 2 Post-operative WBC, CRP, and PCT levels stratified by CRPF

\begin{tabular}{|c|c|c|c|}
\hline & $\begin{array}{l}\text { CRPF group }(n=18) \\
\text { Median (IQR) }\end{array}$ & $\begin{array}{l}\text { Non-CRPF group }(n=168) \\
\text { Median (IQR) }\end{array}$ & Pvalue \\
\hline \multicolumn{4}{|c|}{ WBC $\left(\times 10^{9} / \mathrm{L}\right)$} \\
\hline POD1 & $13.82(10.72-15.52)$ & $12.50(9.94-16.28)$ & 0.242 \\
\hline POD2 & $19.97(15.93-23.36)$ & $16.30(12.47-18.80)$ & 0.003 \\
\hline POD3 & $15.54(12.76-20.01)$ & $12.52(9.91-15.78)$ & 0.001 \\
\hline POD5 & $13.08(10.02-20.82)$ & $9.85(7.72-11.97)$ & 0.009 \\
\hline POD7 & 15.35 (10.91-20.79) & $9.66(7.86-13.24)$ & $<0.001$ \\
\hline \multicolumn{4}{|c|}{$\mathrm{PCT}(\mathrm{ng} / \mathrm{mL})$} \\
\hline POD1 & $1.33(0.70-2.34)$ & $0.31(0.18-0.64)$ & $<0.001$ \\
\hline POD2 & $5.76(3.92-8.21)$ & $0.63(0.40-1.26)$ & $<0.001$ \\
\hline POD3 & $3.88(2.67-6.02)$ & $0.51(0.29-1.00)$ & $<0.001$ \\
\hline POD5 & $1.51(0.94-2.15)$ & $0.32(0.19-0.51)$ & $<0.001$ \\
\hline POD7 & $0.73(0.46-0.99)$ & $0.21(0.14-0.35)$ & $<0.001$ \\
\hline \multicolumn{4}{|c|}{ CRP (mg/L) } \\
\hline POD1 & $81.00(46.80-121.53)$ & $40.44(21.87-71.72)$ & 0.045 \\
\hline POD2 & $247.89(219.44-257.00)$ & $174.57(130.02-237.79)$ & $<0.001$ \\
\hline POD3 & $201.72(141.88-261.45)$ & $179.50(138.12-246.40)$ & 0.081 \\
\hline POD5 & $107.16(70.97-186.72)$ & $89.52(52.45-129.37)$ & 0.007 \\
\hline POD7 & $80.70(73.40-193.69)$ & $51.85(29.25-116.08)$ & 0.001 \\
\hline \multicolumn{4}{|c|}{ DFA (IU/L) } \\
\hline POD3 & $789.75(67.75-3906.50)$ & $32.00(30.00-2802.90)$ & 0.004 \\
\hline
\end{tabular}

CRP C-reactive protein, $W B C$ white blood cell count, $P C T$ procalcitonin, $P O D$ post-operative day, CRPF clinically relevant pancreatic fistula, $L P D$ laparoscopic pancreaticoduodenectomy, IQR interquartile range, DFA drain fluid amylase among patients with CRPF compared to those without CRPF. WBC counts are affected by factors other than inflammation and infection, such as trauma, acute blood loss, and medications, making this a less reliable marker than CRP and PCT levels for predicting CRPF.

CRP is the first acute reactant synthesized in the liver, with a half-life of $19 \mathrm{~h}$. CRP levels rise above normal values within $6 \mathrm{~h}$ and peak at $48 \mathrm{~h}$ after stimulation [23]. Serum CRP levels are determined by the rate of synthesis. In the absence of additional inflammatory stimuli, CRP levels gradually decline after surgery on PODs 2 and 3. However, in the presence of post-operative complications, such as POPF, CRP levels will continued to rise [24]. In this study, post-operative CRP levels in the CRPF group peaked on POD 2, while levels in the non-CRPF group peaked on POD 3. This suggests acute activation of inflammatory stimuli in patients with CRPF after LPD. POPF and elevated CRP levels have been found to be associated with post-operative complications after various abdominal surgeries, including pancreatic [25] and colorectal surgeries [26]. In recent years, several studies have demonstrated that CRP levels can predict POPF development after OPD [27-29]. Kanda et al. [24] reported that a steep rise in serum CRP levels in the early post-operative period was predictive of CRPF after OPD. However, the AUC of the ROC plots for the $\Delta$ (POD3-POD1) CRP level was only 0.767 , and the diagnostic accuracy of PODs 1,3 , and 5 CRP levels was lower (AUC 0.534-0.684). Malya

Table 3 ROC analysis for the prediction of CRPF occurrence after LPD

\begin{tabular}{|c|c|c|c|c|c|c|}
\hline Days & Variables & Cutoff & AUC $(95 \% \mathrm{Cl})$ & $P$ value & Sensitivity & Specificity \\
\hline \multirow[t]{3}{*}{ POD1 } & WBC & 12.44 & $0.576(0.417-0.734)$ & 0.317 & $68.8 \%$ & $51.9 \%$ \\
\hline & $\mathrm{PCT}$ & 0.65 & $0.788^{C}(0.650-0.925)$ & $<0.001$ & $81.3 \%$ & $75.9 \%$ \\
\hline & CRP & 64.58 & $0.625(0.467-0.783)$ & 0.099 & $62.5 \%$ & $68.4 \%$ \\
\hline \multirow[t]{3}{*}{ POD2 } & WBC & 18.84 & $0.695^{\mathrm{a}}(0.541-0.849)$ & 0.010 & $62.5 \%$ & $72.6 \%$ \\
\hline & PCT & 3.30 & $0.931^{\mathrm{C}}(0.875-0.987)$ & $<0.001$ & $81.3 \%$ & $93.7 \%$ \\
\hline & CRP & 216.93 & $0.794(0.711-0.876)$ & $<0.001$ & $87.5 \%$ & $71.5 \%$ \\
\hline \multirow[t]{4}{*}{ POD3 } & WBC & 14.71 & $0.762^{a, b}(0.647-0.877)$ & $<0.001$ & $70.6 \%$ & $72.6 \%$ \\
\hline & PCT & 2.10 & $0.951^{c}(0.903-0.999)$ & $<0.001$ & $88.2 \%$ & $92.9 \%$ \\
\hline & CRP & 201.40 & $0.629(0.495-0.762)$ & 0.081 & $64.7 \%$ & $64.3 \%$ \\
\hline & DFA & 79.50 & $0.694(0.555-0.833)$ & 0.008 & $76.5 \%$ & $70.2 \%$ \\
\hline \multirow[t]{3}{*}{ POD5 } & WBC & 12.70 & $0.732^{\mathrm{a}}(0.600-0.863)$ & 0.002 & $56.3 \%$ & $81.6 \%$ \\
\hline & PCT & 0.91 & $0.930^{\complement}(0.887-0.972)$ & $<0.001$ & $93.8 \%$ & $87.9 \%$ \\
\hline & CRP & 95.01 & $0.702(0.572-0.832)$ & 0.008 & $81.3 \%$ & $60.3 \%$ \\
\hline \multirow[t]{3}{*}{ POD7 } & WBC & 10.90 & $0.776(0.632-0.919)$ & 0.001 & $85.7 \%$ & $60.9 \%$ \\
\hline & PCT & 0.455 & $0.905^{\complement}(0.844-0.966)$ & $<0.001$ & $85.7 \%$ & $86.2 \%$ \\
\hline & CRP & 73.20 & $0.746(0.631-0.861)$ & 0.059 & $85.7 \%$ & $64.5 \%$ \\
\hline
\end{tabular}

There were significant differences in the AUC values obtained from the ROC curves for the ${ }^{a}$ WBC counts and PCT levels, the ${ }^{b}$ WBC counts and CRP levels, and the ${ }^{c} P C T$ and CRP levels ( $P^{<} 0.05$, Delong's test). Bold font indicates significance at the reported analysis

$R O C$ receiver operating characteristic, $A U C$ area under the curve, $C R P C$-reactive protein, $W B C$ white blood cell, $P C T$ procalcitonin, $P O D$ post-operative day, $C R P F$ clinically relevant pancreatic fistula, LPD laparoscopic pancreaticoduodenectomy, DFA drain fluid amylase 


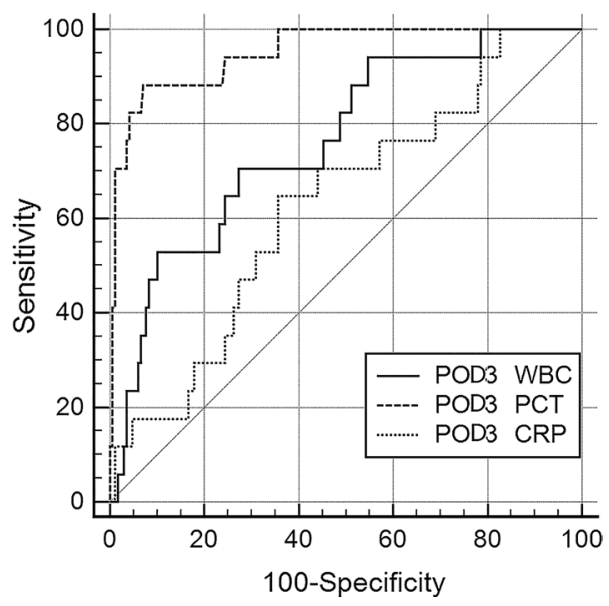

Fig. 2 ROC curves for WBC counts, PCT levels, and CRP levels on POD 3 for predicting CRPF occurrence after LPD. The AUCs of the ROC plots for WBC, PCT levels, and CRP levels were $0.762,0.951$, and 0.629 , respectively. $P C T=2.10 \mathrm{ng} / \mathrm{mL}$ had a sensitivity of $88.2 \%$ and specificity of $92.9 \%$; $C R P=201.4 \mathrm{mg} / \mathrm{L}$ had a sensitivity of $64.7 \%$ and specificity of $64.3 \% ; \mathrm{WBC}=14.7 \times 10^{9} / \mathrm{L}$ had a sensitivity of $70.6 \%$ and specificity of $72.6 \%$. There were significant differences between the ROC analyses ( $P<0.05$, Delong's test). $R O C$ receiver operating characteristic, $C R P C$-reactive protein, WBC white blood count, $P C T$ procalcitonin, $P O D$ post-operative day, LPD laparoscopic pancreaticoduodenectomy

Table 4 Multivariate analyses of predictive risk factors for CRPF in patients undergoing LPD

\begin{tabular}{lllr}
\hline Variables & OR & $95 \% \mathrm{Cl}$ & $P$ value \\
\hline Blood loss (ml) & 1.001 & $0.994-1.009$ & 0.782 \\
BMI $\left(<25 \mathrm{~kg} / \mathrm{m}^{2}\right.$ vs $\left.\geq 25 \mathrm{~kg} / \mathrm{m}^{2}\right)$ & 0.472 & $0.005-4.431$ & 0.511 \\
Pancreatic duct diameter $(<3 \mathrm{~mm}$ & 0.842 & $0.157-4.534$ & 0.843 \\
$\quad$ vs $\geq 3 \mathrm{~mm})$ & & & \\
Gland texture (Soft vs Firm) & 0.282 & $0.019-4.115$ & 0.355 \\
POD3 WBC & 1.269 & $1.081-1.490$ & 0.004 \\
POD3 CRP & 0.996 & $0.982-1.009$ & 0.555 \\
POD3 PCT & 3.303 & $1.902-5.736$ & $<0.001$ \\
POD3 DFA & 1.000 & $0.999-1.000$ & 0.807 \\
\hline
\end{tabular}

$O R$ odds ratio, $\mathrm{Cl}$ confidence interval, $B M I$ body mass index, $C R P C$-reactive protein, $W B C$ white blood cell count, $P C T$ procalcitonin, $P O D$ postoperative day, CRPF clinically relevant pancreatic fistula, LPD laparoscopic pancreaticoduodenectomy, DFA drain fluid amylase

et al. [27] reported that CRP levels $>19 \mathrm{mg} / \mathrm{dL}$ on POD 5 were predictive of CRPF after OPD with a high AUC value (0.851). However, the number of patients with grade $C$ fistula was significantly higher in the study by Malya et al. compared to the current study, which may have led to different results. Guilbaud et al. [28] showed that a serum CRP level $\geq 100 \mathrm{mg} / \mathrm{L}$ on POD 1 was an independent predictor of POPF after OPD. However, the authors included grade A, B, and C POPF in their study. According to the 2016 ISGPS criteria, biochemical leak (grade A fistula) is no longer regarded as a true POPF, and research on CRPF may be more clinically meaningful. It should also be noted that none of the previous studies measured other inflammatory markers.

PCT is considered to be a marker of severe bacterial infections and has the potential to distinguish between infectious and non-infectious systemic inflammation [30]. PCT can also predict anastomotic leakage after colorectal surgery [31, 32]. However, PCT has not been extensively used as an early marker of complications after pancreatic surgery. To date, only a few studies have discussed the role of PCT for predicting complications after OPD. Bianchi et al. [33] showed that PCT on POD 2 was the best predictor of infectious complications after OPD. Another study found that pre-operative PCT levels were superior to pre-operative CRP levels for predicting infectious complications after OPD [17]. Giardino et al. [15] demonstrated that PCT $>0.4 \mathrm{mg} / \mathrm{dl}$ on POD 1 could be an early predictor of CRPF after OPD. Similarly, in the current study, we found that PCT levels were a better predictive marker of CRPF development after LPD compared to CRP levels. PCT is a specific marker for bacterial infections and may not best reflect the inflammatory status (including chemical inflammation caused by pancreatic fistula) unlike CRP [27]. Thus, we hypothesize that POPF following LPD is initiated by biochemical leakage (BL) without signs of infection. However, persistent BL may result in CRPF, which is closely associated with bacterial infection around the anastomotic site [34]. Some studies have classified POPFs as organ-space surgical site infections [18]. Additionally, the inflammatory response following laparoscopic surgery and open surgery differ. Most reported trials showed that CRP peak levels were significantly higher for open cholecystectomy than for laparoscopic cholecystectomy [35, 36]. Similarly, Schwenk et al. [37] reported that CRP levels were lower after laparoscopic surgery than open colorectal resections. This suggests that laparoscopic surgery may weaken the inflammatory response and reduce CRP levels. Several comparison studies between LPD and OPD suggest that LPD is associated with a lower estimated intra-operative blood loss and tissue ischemia, which may further weaken the inflammatory response [38, 39]. We suspect that with the weakening of the inflammatory response, other factors such as infection that cause CRP to rise may become prominent; infection can increase CRP and PCT levels after pancreatectomy [17]. In summary, the good performance of PCT for predicting CRPF after LPD may be related to the weaker inflammatory response following laparoscopic surgery and inevitable concurrent infections. 
Drain fluid amylase content is superior for determining the presence of POPF because it directly reflects the leakage of pancreatic fluids. However, amylase concentration can be strongly influenced by the amount of exudative ascites fluid and the efficacy of drainage [24], indicating that it does not always increase parallel to the exacerbation of POPF. According to the 2016 ISGPS criteria, grade $B$ fistula is diagnosed when there is a clinically apparent symptomatic fistula with persistent drainage $>3$ weeks. Therefore, the diagnosis of CRPF by DFA usually lags behind. In our study, POD3 DFA was of low diagnostic value (AUC 0.694) in the diagnosis of CRPF. This further reflects the importance of inflammatory indicators in early prediction of CRPF. A soft pancreas and small pancreatic duct have been widely reported as risk factors for POPF $[12,40]$. However, when they were combined with inflammatory indicators in multivariate analysis, we found that inflammatory indicators become the predictive risk factors for CRPF. The results of the present study suggest that POD3 PCT could be an important marker used to tailor the post-operative management of LPD patients. When a patient's POD3 PCT is greater than $2.1 \mathrm{ng} / \mathrm{ml}$ after LPD, several preventive measures including early imaging techniques, evaluation of antibiotic treatment, and percutaneous drainage in the presence of intra-abdominal collections may be considered.

The present study has some limitations, including small sample size and the retrospective nature of the study. Future larger prospective studies are required to assess the validity and reliability of the present data. In the future, we plan to design prospective controlled trials to compare the differences in post-operative inflammatory response between LPD and OPD and to assess the ability of inflammatory markers to predict other infectious complications after LPD.

\section{Conclusions}

Both CRP and PCT levels can be used to predict CRPF development after LPD. PCT levels $>2.10 \mathrm{ng} / \mathrm{ml}$ on POD 3 after LPD are superior predictive markers of CRPF compared to CRP levels. Early recognition of CRPF after LPD using these parameters can help surgeons to intervene in the early stages and reduce post-operative morbidity and mortality.

\section{Abbreviations}

PCT: Procalcitonin; CRP: C-reactive protein; WBC: White blood cell; LPD: Laparoscopic pancreaticoduodenectomy; OPD: Open pancreaticoduodenectomy; CRPF: Clinically relevant pancreatic fistula; POPF: Post-operative pancreatic fistula; ROC: Receiver operating characteristic; AUC: Area under the curve; POD: Post-operative day; Cl: Confidence interval; IQR: Interquartile range; OR: Odds ratio; DFA: Drain fluid amylase.

\section{Acknowledgements}

None.

\section{Authors' contributions}

JM: Conceptualization, Data curation, Formal analysis, Investigation; PJ: Conceptualization; Data curation; Formal analysis; Investigation; BJ: Investigation, Methodology; YS: Conceptualization, Supervision, Methodology; YL: Conceptualization, Supervision, Project administration. All authors read and approved the final manuscript.

Funding

None.

\section{Availability of data and materials}

The datasets generated and analyzed during the present study are available from the corresponding author on reasonable request.

\section{Declarations}

\section{Ethics approval and consent to participate}

The study protocol was approved and informed consent was waived due to the retrospective nature of this study by the Ethical Committee of the First Hospital of Jilin University (Ethics Approval Number: 2019-232). All procedures performed in studies involving human participants were in accordance with the ethics standards of the institutional and national research committee and with the 1964 Helsinki Declaration and its later amendments or comparable ethics standards.

\section{Consent for publication}

Not applicable.

\section{Competing interests}

The authors declare that they have no competing interests.

Received: 13 January 2021 Accepted: 22 March 2021

Published online: 30 March 2021

\section{References}

1. Gagner M, Pomp A. Laparoscopic pylorus-preserving pancreatoduodenectomy. Surg Endosc. 1994;8:408-10.

2. Wang M, Peng B, Liu J, Yin X, Tan Z, Liu R, et al. Practice patterns and perioperative outcomes of laparoscopic pancreaticoduodenectomy in china: a retrospective multicenter analysis of 1029 patients. Ann Surg. 2019;273(1):145-53.

3. Rho SY, Kim SH, Kang CM, Lee WJ. Is ICG-enhanced image able to help predicting pancreatic fistula in laparoscopic pancreaticoduodenectomy? Minim Invasive Ther Allied Technol. 2019;28:29-32.

4. Seung LC, Young KE, Kyoung YY, Ho HT. Perioperative outcomes of laparoscopic pancreaticoduodenectomy for benign and borderline malignant periampullary disease compared to open pancreaticoduodenectomy. Langenbecks Arch Surg. 2018:403(5):591-7.

5. Qin H, Qiu J, Zhao Y, Pan G, Zeng Y, Algül H. Does minimally-invasive pancreaticoduodenectomy have advantages over its open method? A meta-analysis of retrospective studies. PLoS ONE. 2014;9:104274.

6. Croome KP, Farnell MB, Que FG, Reid-Lombardo KM, Truty MJ, Nagorney DM, et al. Total laparoscopic pancreaticoduodenectomy for pancreatic ductal adenocarcinoma: oncologic advantages over open approaches?. Ann Surg. 2014:260:633-8 (discussion 8-40).

7. Dokmak S, Fteriche FS, Aussilhou B, Bensafta Y, Levy P, Ruszniewski P, et al. Laparoscopic pancreaticoduodenectomy should not be routine for resection of periampullary tumors. J Am Coll Surg. 2015;220:831-8.

8. Song KB, Kim SC, Lee W, Hwang DW, Lee JH, Kwon J, et al. Laparoscopic pancreaticoduodenectomy for periampullary tumors: lessons learned from 500 consecutive patients in a single center. Surg Endosc. 2020:34:1343-52

9. Boggi U, Amorese G, Vistoli F, Caniglia F, De Lio N, Perrone V, et al. Laparoscopic pancreaticoduodenectomy: a systematic literature review. Surg Endosc. 2015;29:9-23.

10. Ohgi K, Okamura Y, Sugiura T, Ito T, Yamamoto Y, Ashida R, et al. Pancreatic attenuation on computed tomography predicts pancreatic fistula after pancreaticoduodenectomy. HPB (Oxford). 2020;22:67-74. 
11. Sakamoto T, Yagyu Y, Uchinaka El, Morimoto M, Hanaki T, Tokuyasu N, et al. Predictive significance of c-reactive protein-to-albumin ratio for postoperative pancreatic fistula after pancreaticoduodenectomy. Anticancer Res. 2019;39:6283-90.

12. Lao M, Zhang X, Guo C, Chen W, Zhang Q, Ma T, et al. External validation of alternative fistula risk score (a-FRS) for predicting pancreatic fistula after pancreatoduodenectomy. HPB (Oxford). 2020;22:58-66.

13. Lagoutte N, Facy O, Ravoire A, Chalumeau C, Jonval L, Rat P, et al. C-reactive protein and procalcitonin for the early detection of anastomotic leakage after elective colorectal surgery: pilot study in 100 patients. J Visc Surg. 2012;149:e345-9.

14. Dominguez-Comesana E, Lopez-Gomez V, Estevez-Fernandez SM, Marino Padin E, Ballinas-Miranda J, Carrera-Dacosta E, et al. Procalcitonin and C-reactive protein as early indicators of postoperative intra-abdominal infection after surgery for gastrointestinal cancer. Cir Esp. 2014;92:240-6.

15. Giardino A, Spolverato G, Regi P, Frigerio I, Scopelliti F, Girelli R, et al. C-Reactive protein and procalcitonin as predictors of postoperative inflammatory complications after pancreatic surgery. J Gastrointest Surg. 2016;20:1482-92.

16. lida $\mathrm{H}$, Maehira $\mathrm{H}$, Mori $\mathrm{H}$, Tani M. Serum procalcitonin as a predictor of infectious complications after pancreaticoduodenectomy: review of the literature and our experience. Surg Today. 2020;50:87-96.

17. Mansukhani V, Desai G, Shah R, Jagannath P. The role of preoperative C-reactive protein and procalcitonin as predictors of post-pancreaticoduodenectomy infective complications: a prospective observational study. Indian J Gastroenterol. 2017;36:289-95.

18. Angiolini MR, Gavazzi F, Ridolfi C, Moro M, Morelli P, Montorsi M, et al. Role of $C$-reactive protein assessment as early predictor of surgical site infections development after pancreaticoduodenectomy. Dig Surg. 2016;33:267-75

19. Hiyoshi M, Chijiiwa K, Fujii Y, Imamura N, Nagano M, Ohuchida J. Usefulness of drain amylase, serum C-reactive protein levels and body temperature to predict postoperative pancreatic fistula after pancreaticoduodenectomy. World J Surg. 2013;37:2436-42.

20. Ke J, Liu Y, Liu F, Ji B. Application of laparoscopic pancreatoduodenectomy in elderly patients. J Laparoendosc Adv Surg Tech A. 2020;30:797-802.

21. Bassi C, Marchegiani G, Dervenis C, Sarr M, Abu Hilal M, Adham M, et al. The 2016 update of the International Study Group (ISGPS) definition and grading of postoperative pancreatic fistula: 11 Years After. Surgery. 2017; 161:584-91.

22. DeLong ER, DeLong DM, Clarke-Pearson DL. Comparing the areas under two or more correlated receiver operating characteristic curves: a nonparametric approach. Biometrics. 1988;44:837-45.

23. Pepys MB. C-reactive protein fifty years on. Lancet. 1981;1:653-7.

24. Kanda M, Fujii T, Takami H, Suenaga M, Inokawa Y, Yamada S, et al. Novel diagnostics for aggravating pancreatic fistulas at the acute phase after pancreatectomy. World J Gastroenterol. 2014;20:8535-44.

25. Welsch T, Frommhold K, Hinz U, Weigand MA, Kleeff J, Friess H, et al. Persisting elevation of $\mathrm{C}$-reactive protein after pancreatic resections can indicate developing inflammatory complications. Surgery. 2008;143:20-8.

26. Munoz JL, Alvarez MO, Cuquerella V, Miranda E, Pico C, Flores R, et al. Procalcitonin and $\mathrm{C}$-reactive protein as early markers of anastomotic leak after laparoscopic colorectal surgery within an enhanced recovery after surgery (ERAS) program. Surg Endosc. 2018;32:4003-10.

27. Malya FU, Hasbahceci M, Tasci Y, Kadioglu H, Guzel M, Karatepe O, et al. The Role of C-reactive protein in the early prediction of serious pancreatic fistula development after pancreaticoduodenectomy. Gastroenterol Res Pract. 2018;2018:9157806

28. Guilbaud T, Birnbaum DJ, Lemoine C, Chirica M, Risse O, Berdah S, et al. C-reactive protein on postoperative day 1 is a reliable predictor of pancreas-specific complications after pancreaticoduodenectomy. J Gastrointest Surg. 2018;22:818-30.

29. Matsunaga T, Saito H, Murakami Y, Kuroda H, Fukumoto Y, Osaki T. Serum level of C-reactive protein on postoperative day 3 is a predictive indicator of postoperative pancreatic fistula after laparoscopic gastrectomy for gastric cancer. Asian J Endosc Surg. 2017;10:382-7.

30. Brunkhorst FM, Eberhard OK, Brunkhorst R. Discrimination of infectious and noninfectious causes of early acute respiratory distress syndrome by procalcitonin. Crit Care Med. 1999;27:2172-6.

31. Takakura Y, Hinoi T, Egi H, Shimomura M, Adachi T, Saito Y, et al. Procalcitonin as a predictive marker for surgical site infection in elective colorectal cancer surgery. Langenbecks Arch Surg. 2013;398:833-9.

32. Giaccaglia V, Salvi PF, Antonelli MS, Nigri G, Pirozzi F, Casagranda B, et al. Procalcitonin Reveals Early Dehiscence in Colorectal Surgery: The PREDICS Study. Ann Surg. 2016;263:967-72.

33. Bianchi RA, Haedo AS. Romero MC [Role of plasma procalcitonin determination in the postoperative follow-up of cephalic pancreatoduodenectomy. Cir Esp. 2006;79:356-60.

34. Hata T, Mizuma M, Motoi F, Nakagawa K, Masuda K, Ishida M, et al. Early postoperative drainage fluid culture positivity from contaminated bile juice is predictive of pancreatic fistula after pancreaticoduodenectomy. Surg Today. 2019;50(3):248-57.

35. Cho JM, LaPorta AJ, Clark JR, Schofield MJ, Hammond SL, Mallory PL. Response of serum cytokines in patients undergoing laparoscopic cholecystectomy. Surg Endosc. 1994;8:1380-4.

36. Jakeways MS, Mitchell V, Hashim IA, Chadwick SJ, Shenkin A, Green CJ, et al. Metabolic and inflammatory responses after open or laparoscopic cholecystectomy. Br J Surg. 1994;81:127-31.

37. Schwenk W, Jacobi C, Mansmann U, Bohm B, Muller JM. Inflammatory response after laparoscopic and conventional colorectal resections - results of a prospective randomized trial. Langenbecks Arch Surg. 2000;385:2-9.

38. Liu M, Ji S, Xu W, Liu W, Qin Y, Hu Q, et al. Laparoscopic pancreaticoduodenectomy: are the best times coming? World J Surg Oncol. 2019:17:81.

39. Palanivelu C, Jani K, Senthilnathan P, Parthasarathi R, Rajapandian S, Madhankumar MV. Laparoscopic pancreaticoduodenectomy: technique and outcomes. J Am Coll Surg. 2007;205:222-30.

40. Pedrazzoli S, Sperti C. Prevention of Clinically-relevant Postoperative Pancreatic Fistula After Pancreticoduodenectomy. Ann Surg. 2019;269:e7-8.

\section{Publisher's Note}

Springer Nature remains neutral with regard to jurisdictional claims in published maps and institutional affiliations.

\footnotetext{
Ready to submit your research? Choose BMC and benefit from:

- fast, convenient online submission

- thorough peer review by experienced researchers in your field

- rapid publication on acceptance

- support for research data, including large and complex data types

- gold Open Access which fosters wider collaboration and increased citations

- maximum visibility for your research: over 100M website views per year
}

At BMC, research is always in progress.

Learn more biomedcentral.com/submissions 